\title{
Aid and the Delegated Fight against Terrorism
}

\author{
by \\ Jean-Paul Azam, \\ University of Toulouse (ARQADE and IDEI) \\ and Institut Universitaire de France, \\ and

\section{Alexandra Delacroix} \\ SGAM, Paris.
}

\begin{abstract}
This paper brings out a positive empirical relationship between the level of foreign aid received by a country and the number of terrorist attacks originating from it. A simple principal-agent model is used to explain it, emphasizing the delegation by the donor of some actions against terrorism to the aid-recipient government. An econometric test suggests that aid is endogenous in an equation explaining participation in terrorist events, as expected from the model. An attempt at identifying the attacks-supply curve by using some proxies for "militancy", in which aid has a negative impact, is presented at the end.
\end{abstract}

Acknowledgements: This paper is dedicated to the memory of Jean-Jacques Laffont, who wanted to do more work on aid. A previous version has been presented at the HWWA Conference on "The Political Economy of Aid" in Hamburg (12/9/04) and at the "Polarization and Conflict" Conference in Barcelona (12/11/04). Comments by participants and by two anonymous referees, as well as earlier comments and advice by Marc Ivaldi, Eliana La Ferrara and Ariane Tichit, are gratefully acknowledged, without implicating. This research started when Alexandra Delacroix was a DEA student at the University of Toulouse. It is part of the Polarization and Conflict Project CIT-2-CT-2004-506084 funded by the European Commission-DG Research Sixth Framework Programme. This article reflects only the author's views and the Community is not liable for any use that may be made of the information contained therein.

Corresponding Author:

Prof. Jean-Paul Azam,

ARQADE, University of Toulouse 1,

21, Allée de Brienne,

31000 Toulouse, France,

e-mail : azam@univ-tlse1.fr 


\section{Introduction}

George W. Bush linked the issues of aid and terrorism in a much cited speech in Monterrey given on March 22, 2002, where he said: “We fight against poverty because hope is an answer to terror" (cited in Krueger and Maleckova, 2003, p.119). This idea was echoed by various personalities from the U.S. administration, as well as from academia, who developed its implications for strengthening aid policy. This proposition attracted some severe criticism by Alan Krueger in an influential essay published in the New York Times (Krueger, 2003). The bottom line of this criticism is that survey data show that terrorists from different movements, including the Hezbollah, are predominantly recruited from a relatively wealthy and educated family background. Other pieces of evidence are also presented in Krueger and Maleckova (2003) as well as in Krueger and Laitin (2003) that lean in the same direction. Hence, the microeconomic evidence seems to refute a simple view that poverty breeds terrorism, at least as far as individual choice to participate is concerned. It suggests instead that wealth and education exert a positive influence on the decision to engage in terrorist attacks. This is used by some as an argument against the use of aid as a tool in the fight against terrorism, because it is supposed to reduce poverty and promote education, which thus seem to impact positively on terrorist activity. According to this view, then, aid to poor countries should be cut because it would increase the probability of terrorist attacks, by increasing the supply of better off and educated people. Therefore, this debate is bearing on a fundamental aspect of the relationships between the North and the South, and raises the issue of the continuation of foreign aid when the global fight against terrorism is dominating international relations. The present paper is aimed at contributing some light on this debate, using both theoretical and empirical analysis.

The findings described above about the impact of wealth on terrorism also raise a major challenge to economists who want to apply rational choice theory to explain such a behavior. This is not just an academic issue, for if terrorism was definitely an irrational activity, then no serious thinking should be devoted at all to conceiving any type of policy against it. In particular, the issue of the impact of aid on terrorism should then be discarded as hopeless. The issue is that higher wealth and education increase the opportunity cost of 
taking risk in perpetrating a terrorist attack, and still do not seem to act as a deterrent in the real world, at least for those who cross the line. Three main arguments have been offered to reconcile this finding with rationality. The first one is based on the assumption of rationing on the volunteers' market. According to this view, there is an excess supply of volunteers for terrorist missions, and the organizations pick the most educated ones, likely to be more efficient than the others. Bueno de Mesquita (2003) has developed this line of analysis, with a model that endogenizes mobilization and violence. His model suggests that policies improving the economic situation, including may be foreign aid, could nevertheless play a favorable part for reducing mobilization and violence. A different argument is used by Azam (2005), assuming that terrorists are motivated by altruism towards the next generation. People with a lower rate of time preference will invest more resources in education, and will also be more willing to sacrifice their own life for the sake of the future generation. Hence, the effect of education on the opportunity cost of putting one's life at risk might be offset by its positive impact on altruism. That model suggests that some types of aid policies might be effective against terrorism, depending on the effect that they have on the trade off facing the potential terrorists. Berman and Laitin (2003) and Wintrobe (2002) provide a third line of argument, and analyze instead the social pressure dimension of the decision to opt for suicide bombing. These models do not involve much implication for aid policy. However, the former addresses the issue of the relationship between wealth and terrorism described above, suggesting that some subtle indirect effect could yields a negative net effect. The latter three papers view suicide attacks as the ultimate test of the rational choice approach to terrorism. If the latter can be explained rationally, then any less radical terrorist behavior can be explained too.

In September 2002, President Bush came up with a different line of defense for his views about poverty and terrorism. In a New York Times op-ed published on September 11 he wrote: “Poverty does not transform poor people into terrorists and murderers. Yet, poverty, corruption and repression are a toxic combination in many societies, leading to weak governments that are unable to enforce order or patrol their borders and are vulnerable to terrorist networks and drug cartels" (cited in Krueger and Maleckova, 2003, p.140). This 
statement identifies a crucial actor, whose behavior may create the link between economic conditions and terrorism, namely the government. However, his use of the expression "weak government" is somehow ambiguous, and might be misleading. In fact, Krueger and Maleckova (2003) and Krueger and Laitin (2003) find that repressive states are typical of the countries of origin of the perpetrators. Using a cross-country regression explaining the number of international terrorist events originating from each country over 1997-2002, they show that civil liberties have a negative impact on the supply of terrorist events. However, it is a difficult semantic issue whether civil liberties are secured by strong states, or by "weak governments". One can make a convincing case that strong states don't need repression, and are better equipped for securing civil liberties for their citizens. Then, the impact of civil liberties found by Krueger and Maleckova (2003) is in fact providing some support to George Bush's view. However, one potential concern with these findings is the endogeneity issue. One could make a case that the countries from which a lot of terrorists originate are probably characterized by the presence of highly militant groups, which might in turn provide a favorable environment for the emergence of fairly repressive governments. Hence, the presence of a repressive government and the supply of terrorists might in fact result both from the same cause: a high level of militancy among some groups in the population. In other words, tougher governments emerge when there are tougher nuts to crack. Nevertheless, these results show convincingly that the issue of aid and terrorism cannot be settled without bringing in the government as a central actor. The present paper aims at clarifying the relationship between aid and terrorism from both a theoretical and an empirical points of view. It draws two lessons from the debate sketched above, namely that a careful analysis of the role of the government is needed for understanding the links between aid and terrorism, and that the issue of endogeneity is crucial for a proper empirical diagnosis.

This is consistent to some extent with the theoretical literature on aid, which is largely couched in the framework of the principal-agent model, where the recipient government is regarded as the agent and the foreign power as the principal. There is now a sizable literature discussing various aspects of aid, which has percolated somewhat in the policy 
debate (e.g. World Bank, 1998). The basic structure of the theoretical models of aid views the aid relationship in a contract-theoretic framework where the recipient government is an agent who is supposed to perform some tasks on behalf of a foreign power, the donor. Both players have some common interest, which is widely assumed to be poverty alleviation, albeit with different weights (Adam and O'Connell, 1999, Azam and Laffont, 2003, Svensson, 2000 and 2003). Then, the aim of the analysis is to bring out the implementation problems to be solved in order for aid to be effective, by the donor's standards. Hence, this theoretical framework could be used as well even if poverty alleviation was not assumed to be the true objective pursued by the foreign power. Azam and Saadi-Sedik (2004) go one step further in the analysis by looking at the choice made by the foreign power between giving aid and imposing sanctions with a view to change the recipient government's behavior. They provide a case study of the fate of the Iraqi Kurds after the "Provide Comfort" operation was launched, i.e. when this group benefited from some protection against Saddam Hussein's persecution. They conclude that it was highly beneficial for this previously victimized group, who benefited from some economic growth under the military shield provided by the allied forces. The model used in section 3 below is a very simple instance of this type of principalagent models, where the donor is using the recipient government as a delegate for performing some tasks on its behalf. Aid is thus viewed as an incentive for adopting a behavior more in line with the donor's concerns.

The empirical literature on the allocation of aid across developing countries has also adopted to some extent the restrictive view that aid should be mainly targeted at poverty alleviation. Nevertheless, it also takes on board some political economy dimension. Aid to developing countries has been increasingly delivered as program aid, conditional upon the recipient government undertaking various policy reforms. This approach is thus broadly consistent with the principal-agent framework sketched above. The highly influential paper by Burnside and Dollar (2000) has brought out forcefully that the effect of aid must be analyzed while taking due account of some heterogeneity among recipient countries. They favour an index of the quality of macroeconomic policies as their heterogeneity parameter. However, their results suggest that aid-effectiveness, as measured by its impact on growth 
and development is probably not the crucial determinant of the allocation of aid across countries. Using also cross-country regression analysis, Svensson (1999) shows that aid is more effective in affecting growth in more democratic countries, but is not allocated to the latter more favourably. Hence, this "aid-ineffectiveness" literature is also suggesting that aid allocation is governed in the real world by other considerations than growth and poverty alleviation, which scholars have mainly emphasized. There is thus probably a hidden agenda beside the generous drive to alleviate poverty.

This is the issue analyzed by Alesina and Dollar (2000), who show that colonial past and strategic alliances are the main determinants of the amount of aid received. However, they also show that, in the time series dimension, democratisation is often followed by increased aid, although there is no significant static effect of democracy. Mobutu's Zaire is an example of a non democratic country which received aid continuously, for cold war-related reasons. Many oppressive dictatorships in Africa and Asia have received aid. This has changed somewhat recently, and General Abacha's Nigeria, for example, was denied any aid for political reasons, after killing some representatives of the Ogoni people. The question arises whether giving aid to such dictators is legitimate, or whether the international community should reserve aid to 'good governments'. However, denying aid systematically to oppressive regimes would exclude from the list of potential recipients a large fraction of the developing world, and thus does not seem feasible. By contrast, Berthélemy and Tichit (2004) find a significant positive impact of the Freedom House index of civil liberty and political right, in a panel data analysis covering the period 1980-1999, for 137 aid recipient countries, and 22 bilateral donors. This is confirmed in a later study, using a different estimation method (Berthélemy, 2004). Nevertheless, the latter two studies bring out quite strongly that most bilateral donors are also guided by their self-interest for allocating their aid, and in particular by their commercial relationships. The results reported by Fleck and Kilby (2004) suggest that the validity of such a diagnosis can be extended to the case of the World Bank, whose aid-allocation behaviour is significantly influenced by U.S. trading and political interests. Here again, however, one may wonder whether trading flows are perfectly exogenous, at least as far as bilateral donors are concerned. Although most of the latter have 
formally ruled out tied aid, towards the end of that sample period, some implicit and subtle ways of tying aid remain probably in operation. Moreover, aid helps financing the trade deficit of developing countries, and this is bound to boost the imports from industrialized donors. Hence, some reverse causation between aid and trade might also be at work.

Chauvet (2002) looks at the relationship between aid allocation across countries and socio-political instabilities. The latter refers to various events that reflect political problems in the recipient countries. She distinguishes: (i) elite instability, including coup d'etat, revolutions, and major government crises; (ii) violent instability, including political assassinations, guerrilla warfare, and civil wars; and (iii) social instability, including strikes, demonstrations and riots. She shows that these three types of events have different impacts on the allocation of aid, depending also on the kind of aid. Instabilities of types (i) and (ii) have a positive impact, while type (iii) has a negative one. This suggests that the aid flow is somewhat directed at governments that are under political threat, while it shies away from the threats that are directed more specifically at the economy. These results are again providing some support to a view where the donors are giving aid to recipient governments in response to some political motivation, rather as a simple contribution to international poverty alleviation.

The present paper is also analyzing a political dimension of the allocation of aid across countries, by looking at its relationship with terrorism. However, we are not looking at the indirect link between aid and poverty, and then in turn to the additional link between poverty and terrorism, as done in the debate mentioned above, involving indirectly George Bush and Alan Krueger. We are instead looking here at the direct link between aid and terrorism, without explicit mention of the role played by poverty in the transmission mechanism. Section 2 discusses some empirical evidence, based on a similar data set to the one used by Krueger and Maleckova (2003) and Krueger and Laitin (2003). We thus focus on the number of terrorist events per country of origin of the perpetrators. These data can be found on the internet, from the database provided by the International Policy Institute for Counter-Terrorism (ICT). We have extended their sample to cover the period from January 1990 to March 2004. After a thorough search for robust correlation, we have found that the 
amount of aid received by the country of origin is a statistically significant determinant of the number of terrorist attacks originating in any given country, with a positive impact, in a parsimonious cross-country equation. This is the empirical puzzle to which this paper is devoted. Section 3 offers a possible theoretical interpretation for these results. It sets up a simple principal-agent model, where the donor is giving aid in return for some effort made by the recipient government for fighting terrorism within its sphere of influence. As mentioned above, the model does not spell out whether poverty alleviation is a link in the chain between the government's effort and its impact on the flow of terrorist attacks originating from its country. We keep an agnostic view on this, so that our channel of impact may be viewed as a black box. It is up to the recipient government to choose the most efficient policy tools for doing its job, and whether poverty alleviation should be part of the package is an open question. Nevertheless, "fighting poverty" is an important buzz word helping probably to attract the taxpayers' support in donor countries, as shown by the Millenium movement. Then, aid money is probably quite fungible, and no earmarking to poverty alleviation could be a very tight constraint on the choice made by the recipient government (Feyzioglu et al., 1998).

The comparative statics of this model shows that the amount of aid received and the supply of terrorist attacks may move jointly along a positively sloped locus, as the heterogeneity parameter called "militancy" changes, under some parameter restriction. This locus is akin to an Engel's curve in the aid and attacks space. This result yields a testable prediction, namely that aid should be endogenous in the empirical equation presented in section 2. This is tested in section 4, which rejects the exogeneity assumption. This entails that the fight against terrorism does probably figure in the list of the interests of the donor's country that recipient governments are supposed to protect in return for foreign aid. Of course, this paper does not claim that it is the unique motive for foreign aid, or that the traditional goals are just window dressing. The bottom line of this analysis is thus that we find a positive relation between aid and the supply of terrorist attacks not because aid has a pernicious influence, but because (i) aid has a beneficial influence against the supply of terrorist attacks, and, therefore (ii) donor countries are giving more aid to governments of 
countries where more dangerous people come from. Section 5 presents an attempt at identifying the attacks supply curve by adding some dummy variables aimed at capturing some determinants of militancy. They do a reasonably decent job, as a negatively sloped relation is then found, providing some additional support to the theoretical framework.

\section{The Empirical Puzzle}

The data are computed from a set of 1119 terrorist incidents, taking place between January 1990 and March 2004. These events are then aggregated over this period to produce a number of attacks originating from each country. Although $88 \%$ of these events take place in the perpetrators' own countries, they are all regarded as international attacks, because the nationality of the target is different. An analysis of the targets is beyond the scope of the present paper, but Krueger and Laitin (2003) and Delacroix (2004) contain some analysis of this information. During the period under study, 86 countries have produced terrorist attacks. The top twelve source countries are presented in table 1, while the complete set is given in appendix 1.

Table 1: Top 12 Source Countries

$\begin{array}{cccc}\text { Country } & \text { Number of Events } & \text { Country } & \text { Number of Events } \\ \text { India } & 400 & \text { Algeria } & 47 \\ \text { Colombia } & 227 & \text { Pakistan } & 45 \\ \text { Israel } & 97 & \text { Angola } & 41 \\ \text { Iraq } & 58 & \text { Russian Federation } & 33 \\ \text { Yemen } & 49 & \text { Spain } & 31 \\ & 49 & \text { Turkey } & 28\end{array}$

Source: ICT (http://www.ict.org.il).

These data can be used for the purpose at hand, namely analyzing the relationship between aid and the supply of terrorist attacks by the recipient country. The discussion in the introduction has suggested that it is worth distinguishing the effect of aid per se from the 
effect of poverty or wealth. Table 2 presents the results from a series of direct estimations, adding a small number of explanatory variables for the sake of control. It presents three equations explaining the number of terrorist events originating from each country, estimated on a 178-country sample. This sample thus includes both developed and developing countries, as well as aid recipients and donors. The latter have a zero observation for ODA (Official Development Assistance). However, there are some examples of donor countries from which some terrorists came from, like France, Ireland, Spain, etc. Afghanistan, Azerbaijan, Cuba, Iraq, North Korea, Libya, Myanmar, Somalia, Yugoslavia, as well as many small countries, are not included in the sample, because of missing data on GDP. The latter variable is used in some other equations below. Because the dependent variable is an integer count variable, with a quite large number of zeroes, such equations should not be estimated by OLS. The Negative Binomial regression technique was used instead (see e.g. Maddala, 1983). However, for the sake of reference, the Poisson regression and the OLS one are also presented in the table. As both source and non-source countries are included in the sample, no selectivity problem should be expected. Equations 1 and 2 are yielding roughly the same picture, although they are estimated by a different integer count method. The former uses the Negative Binomial regression technique, while the latter is a Poisson regression. As the latter can be derived from the former by restricting one parameter, it is straightforward to perform a $\chi^{2}$ test for comparing them, using the log-likelihood statistics. This test rejects the Poisson restriction by a wide margin.Equation 1 was also estimated on the enlarged sample obtained by including eight of the countries listed above, with the exception of North Korea. Another $\chi^{2}$ test (with 8 degrees of freedom) rejected the assumption that there was any parameter instability across the two samples. Equation 3 is the OLS estimation of the same equation. The estimates are not widely different from the previous ones, as far as the coefficients are concerned. However, the attached t-statistics do not yield the same diagnosis as the z-statistics of the other two equations. Nevertheless, these equations suggest quite convincingly that there is a robust positive relationship between the number of terrorist events originating form each country and the amount of ODA that it receives. 
Table 2: Number of Terrorist Events Originating from Country $i$

\begin{tabular}{|c|c|c|c|c|c|c|c|c|c|}
\hline & Equation 1 & & & Equation 2 & & & Equation 3 & & \\
\hline Variables & Coefficient & z-Statistics & $\mathrm{p}$-value & Coefficient & z-Statistics & $\mathrm{p}$-value & Coefficient & t-Statistics & $p$-value \\
\hline Intercept & 0.61 & 4.14 & 0.000 & 1.42 & 37.42 & 0.000 & 1.54 & 0.48 & 0.64 \\
\hline ODA & 0.003 & 8.13 & 0.000 & 0.0008 & 16.86 & 0.000 & 0.009 & 1.23 & 0.23 \\
\hline Population & 0.013 & 3.98 & 0.000 & 0.009 & 19.69 & 0.000 & 0.18 & 2.15 & 0.03 \\
\hline$(\text { Population })^{2}$ & $-1.52 \mathrm{E}-05$ & -4.61 & 0.000 & $-6.86 \mathrm{E}-06$ & -17.48 & 0.000 & $-1.09 \mathrm{E}-04$ & -1.50 & 0.13 \\
\hline Nb. Obs. & 178 & & & 178 & & & 178 & & \\
\hline$R^{2}$ & - & & & - & & & 0.10 & & \\
\hline Pseudo- $R^{2}$ & 0.13 & & & 0.20 & & & - & & \\
\hline LR-Stat. (3 df) & 148.67 & & & 1312.7 & & & F-Stat: 6.49 & & \\
\hline p-value & 0.000 & & & 0.000 & & & 0.000 & & \\
\hline
\end{tabular}

Note: Equation 1 is a negative binomial regression estimated by quasi-maximum likelihood. Equation 2 is a Poisson regression, estimated by maximum likelihood. Equation 3 is a simple OLS regression. The dependent variable is the number of terrorist events originating from each country during the period 1990:01-2004:03. 
Table 3: Number of Terrorist Events Originating from Country I (Cont.d)

\begin{tabular}{|c|c|c|c|c|c|c|c|c|c|}
\hline & Equation 4 & & & Equation 5 & & & Equation 6 & & \\
\hline Variables & Coefficient & z-Statistics & p-value & Coefficient & z-Statistics & p-value & Coefficient & t-Statistics & $\mathrm{p}$-value \\
\hline Intercept & 0.73 & 4.05 & 0.000 & 1.61 & 36.47 & 0.000 & 2.97 & 0.75 & 0.45 \\
\hline ODA & 0.0028 & 6.86 & 0.000 & 0.0006 & 11.86 & 0.000 & 0.007 & 0.87 & 0.39 \\
\hline Population & 0.013 & 4.14 & 0.000 & 0.009 & 19.75 & 0.000 & 0.09 & 2.24 & 0.03 \\
\hline$(\text { Population })^{2}$ & - 1.54E-05 & -4.74 & 0.000 & - 7.402E-06 & -17.53 & 0.000 & - 1.02E-04 & -1.60 & 0.11 \\
\hline GDP p.c. & - 1.27E-05 & -1.12 & 0.260 & $-3.07 \mathrm{E}-05$ & -6.95 & 0.000 & $-1.9 \mathrm{E}-04$ & -0.64 & 0.52 \\
\hline $\mathrm{Nb}$. Obs. & 178 & & & 178 & & & 178 & & \\
\hline$R^{2}$ & - & & & - & & & 0.10 & & \\
\hline Pseudo- $R^{2}$ & 0.13 & & & 0.21 & & & - & & \\
\hline LR-Stat. (4 df) & 149.89 & & & 1371.56 & & & F-Stat: 4.96 & & \\
\hline p-value & 0.000 & & & 0.000 & & & 0.001 & & \\
\hline
\end{tabular}

Note: Equation 4 is a negative binomial regression estimated by quasi-maximum likelihood. Equation 5 is a Poisson regression, estimated by maximum likelihood. Equation 6 is a simple OLS regression. The dependent variable is the number of terrorist events originating from each country during the period 1990:01-2004:03. 
In the first two equations, ODA comes out significantly positive, as announced above. Notice that, because population size is controlled for separately, ODA is included per country, and not per capita. Within the theoretical framework developed below, where aid concerns basically a transaction between the donor and the recipient government, as in most of the theoretical aid literature, there is an additional argument in favor of this specification: each country has just one government, independently of its population size, at least as far as the country's international relations are concerned. Hence, insofar as aid is an incentive given to the government, it is fitting that it enters the equation without being divided by population size. However, of course, population size is probably related to the need to intervene felt by the donor, but this does not imply that a linear restriction is warranted ex ante, without testing. In fact, we control for population size using a quadratic specification, as is common in the literature (see e.g. Berthélemy and Tichit, 2004). This non-linear specification captures the idea that although participation in terrorist activity concerns only a tiny fraction of the population in any country, this fraction decreases gradually as the population of origin increases.

A first series of checks is presented in table 3. GDP per capita is added to the previous three equations, with a view to test whether ODA was not spuriously capturing the effect of income on terrorism. Because aid is mainly targeted at poor countries, it is thus natural to check that equation 1 is not capturing the effect of low income on terrorism via its correlation with ODA. Per capita GDP has a significantly negative coefficient as suggested by common sense, in the Poisson regression equation 5. However, it is insignificant in the other two equations. As mentioned in the introduction, there are arguments showing that this relationship between income and terrorism is not obvious. In particular, Krueger and Maleckova (2003) show that the opposite sign is found when they estimate participation equations for Hezbollah terrorists, as well as when they present some of their cross-country estimates. They conclude that there is little direct connection between poverty, education, and participation in terrorist activity. Moreover, their equations suggest that per capita GDP may have a significant negative impact in such equations because it is a proxy for civil liberties, and not in its own right. There is no need to test for this issue in this paper, which 
focuses on the effect of ODA. Thus, per capita GDP is simply a fine control variable to have in our equations, without putting too much emphasis on its precise interpretation. The crucial point that is coming out of table 3 is that its impact, whether it is significant or not, does not affect the sign and significance of the impact of ODA on the number of terrorist attacks originating from each country.

\section{A Suggested Interpretation}

Now, we model a donor that allocates aid between a number of countries, which are liable to produce some terrorist attacks against the donor. In each of these countries, the government is able to exert some effort for fighting terrorism, at a cost. Then, aid is a way to defray the recipient government for this cost of effort. The government's action exerts its influence on the value of a terrorist "hit" for the activists, which also depends on some idiosyncratic "militancy" parameter. Hence, for each country, three players are involved: the terrorist group determines the number of attacks perpetrated against the donor, the local government is exerting some effort to deter these actions, while the donor provides some aid for compensating the government.

\section{The Model}

We capture this framework using the following specification. Denote $Y$ the given income of the donor, $A$ the total amount of aid delivered, and $H$ the total number of hits received from the terrorists coming from the different countries. For each terrorist event, the donor is assumed to be able to identify its country of origin with certainty. Assume that the donor country incurs a cost $\psi(H)$ because of these attacks $\left(\psi^{\prime}(H)>0, \psi^{\prime \prime}(H)>0\right)$. Now, denote $a_{i}$ the aid given to country $i \in\{1, \ldots, n\}$, and $h_{i}$ the number of attacks originating in $i$. Then, by definition, $A=\sum_{i} a_{i}$ and $H=\sum_{i} h_{i}$.

Country i's government exerts an effort $e_{i}$ and incurs in so doing a cost $\xi\left(e_{i}\right), \xi^{\prime}\left(e_{i}\right)>0, \xi^{\prime \prime}\left(e_{i}\right) \geq 0$. Its participation constraint is thus:

$$
U_{i}=a_{i}-\xi\left(e_{i}\right) \geq 0 \text {. }
$$


Notice that (1) could encompass the case of the so-called "rogue states", for whom the cost of fighting terrorism is crippling, may be because they share in fact the views of the terrorists. Then, $\xi\left(e_{i}\right)$ would be very high. However, a proper treatment of this case would possibly have to allow for the use of sanctions, as in Azam and Saadi-Sedik (2004), as well as for moral hazard.

The terrorist organization from the same country attaches a unit value $\theta_{i} v\left(e_{i}\right), v^{\prime}\left(e_{i}\right)<0, v^{\prime \prime}\left(e_{i}\right) \geq 0$ to the attacks, where $\theta_{i}$ is the "militancy" parameter, assumed known to both the donor and the government, and $v\left(e_{i}\right)$ is the decreasing function that captures the negative impact of the government's effort on the value of the "hit" to the terrorist organization. The latter also incurs for perpetrating their attacks a cost $\omega\left(h_{i}\right), \omega^{\prime}\left(h_{i}\right)>0, \omega^{\prime \prime}\left(h_{i}\right)>0$.

The time line of the game is as follows: (i) the donor offers to the government the following contract: "I give you $a_{i}$ if you exert the effort level $e_{i}$ in fighting the terrorists"; (ii) if the contract is accepted, the government exerts the agreed level of effort $e_{i}$, assumed perfectly observable and contractible by the two parties; (iii) the terrorists launch their chosen number of attacks $h_{i}$; and lastly (iv) the aid is delivered and consumed. Hence, this game can be solved by backward induction. We first derive the "hit-supply" curve at the level of the terrorist organization. The "attacks supply" curve is then derived at the country level, by bringing in the government, and the equilibrium locus across countries is derived last.

Now, the terrorist organization chooses its level of attacks with a view to maximize:

$$
\theta_{i} v\left(e_{i}\right) h_{i}-\omega\left(h_{i}\right) .
$$

The first-order condition for this problem is:

$$
\theta_{i} v\left(e_{i}\right)=\omega^{\prime}\left(h_{i}\right),
$$

from which the following "hit-supply" curve can be derived:

$$
h_{i}=h\left(\theta_{i}, e_{i}\right) \text {, }
$$


such that:

$$
\frac{\partial h_{i}}{\partial \theta_{i}}=\frac{v\left(e_{i}\right)}{\omega^{\prime \prime}\left(h_{i}\right)}>0 \text { and } \frac{\partial h_{i}}{\partial e_{i}}=\frac{\theta_{i} v^{\prime}\left(e_{i}\right)}{\omega^{\prime \prime}\left(h_{i}\right)}<0
$$

The signs of these two partial effects are fairly intuitive, and do not call for much comment: more militant groups produce more attacks, while a greater effort by the government reduces the number of attacks.

\section{The Attacks Supply Curve}

Now, the donor is seeking to maximize:

$$
\max _{a_{i}} Y-A-\psi(H)
$$

subject to (1) and (4). This entails first that (1) will be binding in equilibrium as the donor has no reason to leave any positive rent to the recipient government. The aid flow just covers the cost of effort. This produces a one-to-one relationship between $a_{i}$ and $e_{i}$, such that the latter is an increasing function of the former, with:

$$
\frac{d e_{i}}{d a_{i}}=\frac{1}{\xi^{\prime}\left(e_{i}\right)}>0
$$

Then, solving (6) allows to establish proposition 1.

Proposition 1: The number of terrorist attacks originating from country $i$ can be written as the following structural equation:

$$
h_{i}=h\left(\theta_{i}, a_{i}\right)
$$

such that:

$$
\frac{\partial h_{i}}{\partial \theta_{i}}=\frac{v\left(e_{i}\right)}{\omega^{\prime \prime}\left(h_{i}\right)}>0 \text { and } \frac{\partial h_{i}}{\partial a_{i}}=\frac{-1}{\psi^{\prime}(H)}<0
$$

Proof: From problem (6), and taking due account of the constraints, the first-order condition can be written as: 
$\frac{\partial h_{i}}{\partial a_{i}}=\frac{\partial h_{i}}{\partial e_{i}} \frac{d e_{i}}{d a_{i}}=\frac{-1}{\psi^{\prime}(H)}<0$.

The other derivative comes from (5) above.

Proposition 1 assumes that the following second-order condition holds:

$$
\frac{\omega^{\prime \prime \prime}\left(h_{i}\right)}{\omega^{\prime \prime}\left(h_{i}\right)}<\frac{\omega^{\prime \prime}\left(h_{i}\right)}{\omega^{\prime}\left(h_{i}\right)} \frac{v\left(e_{i}\right)}{v^{\prime}\left(e_{i}\right)}\left[\frac{v^{\prime \prime}\left(e_{i}\right)}{v^{\prime}\left(e_{i}\right)}-\frac{\xi^{\prime \prime}\left(e_{i}\right)}{\xi^{\prime}\left(e_{i}\right)}\right] .
$$

The latter ensures that the attacks supply curve is convex, yielding an interior solution (see figure 1). It requires that the cost function of the terrorist organization does not become "too convex". This holds, for example, with the familiar quadratic cost function.

Proposition 1 entails that there exists a well-defined structural relation (8) that expresses the number of terrorist events as a function of the level of aid granted to the government, and of the militancy parameter. Condition (10) entails that aid is effective in this model, in that more aid reduces the number of attacks. Moreover, condition (10) implies that the slope of the attack-supply curve in the $\left\{h_{i}, a_{i}\right\}$ space, which measures the marginal impact of aid on the number of attacks, is equalized across countries at the equilibrium point. This will be used below for graphical purposes.

\section{The Equilibrium Locus}

Let us now compare the equilibrium outcomes across countries, as we are doing implicitly in the cross-country regression exercises performed in the empirical sections 2 above, and 4 and five below. The main result is captured by proposition 2 .

Proposition 2: The co-movement of $h_{i}$ and $a_{i}$ across all countries traces out a positively sloped locus if:

$$
\frac{\xi^{\prime \prime}\left(e_{i}\right)}{\xi^{\prime}\left(e_{i}\right)}>\frac{v^{\prime \prime}\left(e_{i}\right)}{v^{\prime}\left(e_{i}\right)}-\frac{v^{\prime}\left(e_{i}\right)}{v\left(e_{i}\right)}
$$

Proof: Condition (12) is simply derived by some tedious calculations from the comparative statics of the equilibrium point after substituting out $\theta_{i}$. 
Condition (12) requires that the marginal cost of effort faced by the recipient government increases quite sharply, while its impact on the value attached by the terrorists to the attacks is relatively weak, or weakening quite sharply with the level of effort. Notice how (12) makes condition (11) more stringent. These two conditions imply that the effectiveness of the government's effort at reducing the value of the attacks to the terrorists is relatively weak relative to its level. This set of conditions fits a world where terrorists have a definite advantage in their fight against the donor and the government. They are facing a well exposed target that delegates its protection to relatively inefficient agents.

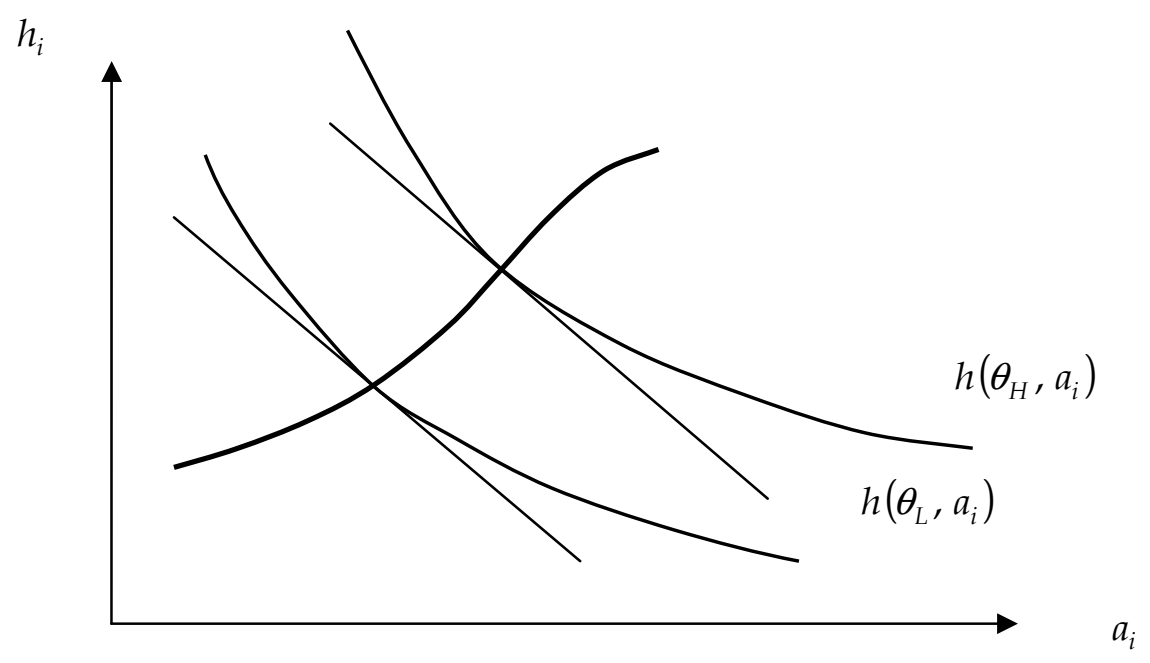

Figure 1: Tracing Out the Equilibrium Locus

Figure 1 helps to grasp more intuitively the thrust of the argument developed in this section. The indifference curves of two recipient governments are represented by the downward sloping convex curves. These represent in fact the attack-supply curves (8) of two governments that differ by the degree of militancy that they are facing in their own country. The interpretation of these curves as indifference curves comes from the participation constraint (1), holding with equality. The upper curve represents the case of a country facing a higher level of militancy than the lower curve. Because the slope of these supply curves are equalized in equilibrium across countries, as seen above, their tangents at the equilibrium points must be parallel. Then, the line linking all such equilibrium points across all the 
countries is the equilibrium locus described at proposition 2. This equilibrium locus must be understood as a partial equilibrium relation, given $H$. Appendix 2 completes the analysis for determining the latter.

Now, this result is of some help in explaining our empirical results found in the previous section if we further assume that the researcher does not know the militancy parameter in each country, or omits it for some other reason, and is thus unable to identify the structural equation (8). Then, estimating across countries the relationship between the number of attacks and the amount of aid given without controlling appropriately for this unobservable heterogeneity would simply result in estimating the equilibrium locus represented at figure 1 . Moreover, in view of (9), the attack-supply curve (8) would be best estimated using panel data, even if "militancy" was observed, in order to allow for enough variation in $H$, which is the same for every country at a moment in time. Otherwise, the researcher would have to rely on random shocks affecting the aid allocation across countries.

\section{The Case of Asymmetric Information}

So far, we have assumed that both the donor and the government have the same information about the militancy parameter, which they know for sure. In the real world, this would probably entail that the governments involved collaborate fully for sharing intelligence. In order to underscore the importance of this assumption, we now show that asymmetric information does not work in the right direction in this model. In other words, we would reach a different conclusion if we assumed that the militancy parameter is the southern government's private information, while the donor only knows a probability distribution over this parameter. In order to bring out this point, we simply sketch the analysis of the case of two types only, assuming also that the recipient government's effort against terrorism is not observed by the donor. Then, the contract specifies the number of attacks perpetrated as a function of the aid level.

Examination of figure 1 brings out easily the incentive compatibility problem entailed by asymmetric information. Remember that the attack-supply curves may be interpreted as indifference curves for the recipient governments. The higher up they are in the northeasterly direction in this space, the higher is their welfare level, because they receive more 
aid, and exert less effort. Hence, all the recipient governments have an incentive to pretend that they are facing very hard nuts to crack, in order to get a more favorable deal from the donor. Then, contract theory tells us that the principal should offer to the agent a choice of contracts that provides the right incentive for revealing the relevant private information (Laffont and Martimort, 2002). The principal is then facing a trade off between rent extraction and efficiency, as eliciting the private information often requires a loss of efficiency.

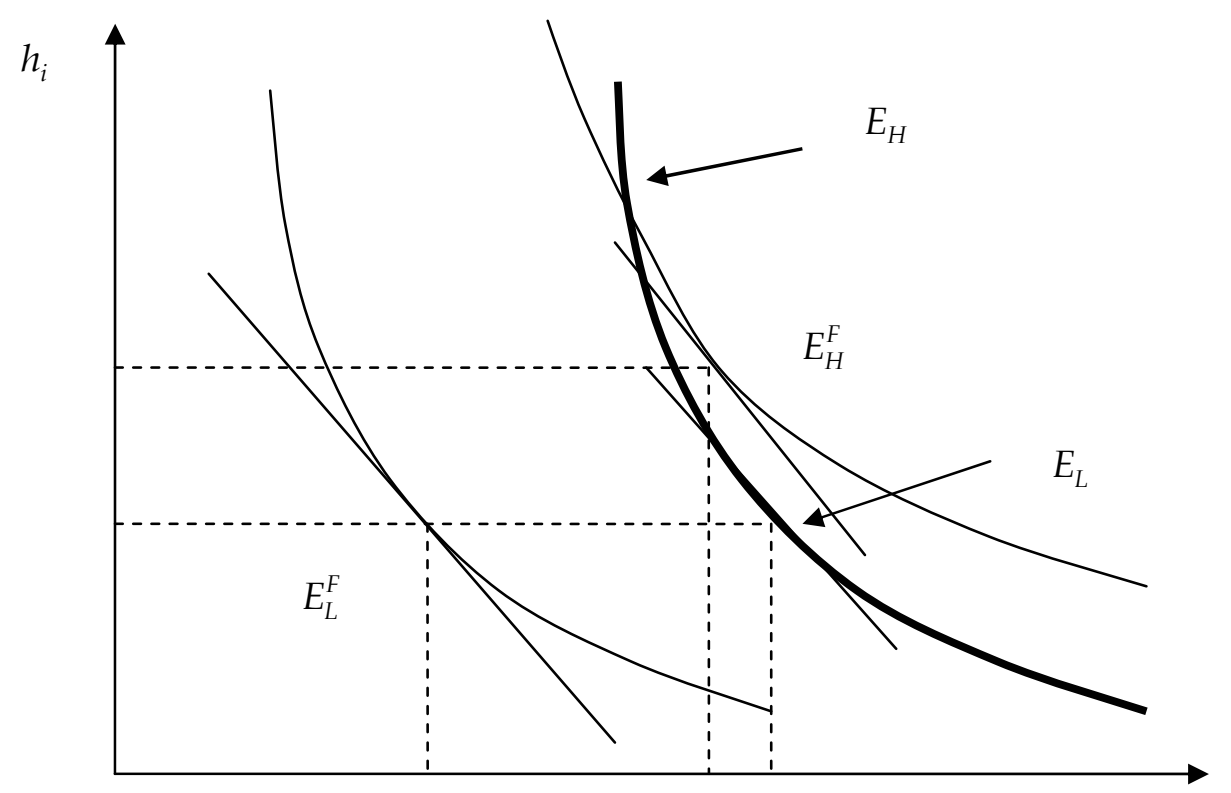

$a_{i}$

Figure 2: The Case of Asymmetric Information

Here, the analysis is straightforward. Assume that the recipient government knows whether the activists that it is facing are of the $\theta_{L}$ or of the $\theta_{H}>\theta_{L}$ type, while the donor only knows that the $H$-type occurs with probability $\pi$. Then, the latter will present the recipient government with the choice to make between two contracts, granting a different level of aid in return for a different number of attacks. Figure 2 helps to bring out the characteristics of these contracts.

Notice first that the recipient government's objective function may be written as:

$$
U_{i}=a_{i}-\xi\left(h^{-1}\left(\theta_{i}, h_{i}\right)\right)
$$


This is a quasi-linear utility function, so that the slope of its indifference curves only depends on $h_{i}$. In other words, a higher level of utility is represented by a rightward shift of the indifference curve, without changing the slope.

Then, figure 2 can be used to determine how the classic rent extraction/efficiency trade off is solved in this case. More aid is given to the $L$-type government, relative to the full information equilibrium, thus giving a rent to this type of government. This is illustrated by the horizontal shift from point $E_{L}^{F}$ to point $E_{L}$. The new welfare level achieved by the L-type government is represented by the indifference curve through $E_{L}$, drawn with a thicker line. In order to ensure that this type of government will not choose a contract meant for a $H$-type one, the contract offered to the latter type must not yield a point located above the resulting indifference curve. This is avoided by imposing a distortion relative to the full information case to the $H$-type government, by moving to point $E_{H}$, along the same indifference curve as the full-information $E_{H}^{F}$. Then the menu of contracts represented by $\left\{E_{L}, E_{H}\right\}$ is fully revealing. Of course, the precise amplitude of the rent given to the $L$-type and the distortion imposed on the $H$-type depends on their respective probabilities. A larger value of $\pi$ will induce the donor to reduce the distortion imposed on the $H$-type, now more probable, and to increase the rent left to the $L$-type, now less probable. This would be represented on figure 2 by a further rightward shift of the indifference curve drawn with a thicker line.

The claim made above that asymmetric information does not work in the right direction in this model is then easily checked by looking at the diagram. There is a negative relationship between aid and the number of attacks across government types, as $E_{H}$ is located to the north-west of $E_{L}$ in figure 2. It is readily checked that this proposition is quite robust, and does not depend too much on the quasi-linear specification. Provided that the single-crossing condition holds, and that we rule out "rogue states", the two equilibrium contracts must lie on the same indifference curve of the L-type government, even if the $E_{H}$ and $E_{L}$ equilibria swap their positions along that curve. Hence, the negative slope follows, unless we are dealing with a type of "rogue state" that attaches a positive value to the attacks. Therefore, the positive impact of ODA found in table 2 suggests that asymmetric 
information between the donor and the recipient governments about the degree of militancy that they are facing is not a useful assumption for understanding this relationship.

\section{Testing for Endogeneity}

The model presented above provides an explanation for the positive relationship between the participation in terrorist events of the nationals from a given country and the amount of aid received by the latter. It suggests that this relationship should be interpreted as an equilibrium locus, akin to an Engel's curve, linking two endogenous variables for different values of some unobserved parameter. Another useful analogy for this equilibrium locus would be the equivalent for cross-country data of a co-integration relation, as used in time-series analysis. More precisely, the model presented above suggests that this positive relationship captures the response of the equilibrium attacks/aid pair to changes in the degree of militancy of the potential terrorists. Within the principal-agent framework used here, this relationship should not be interpreted as a "terrorist-events" supply curve, but as an equilibrium locus that describes the co-movement of these two variables instead. Therefore, the estimated equations presented at table 2 are not necessarily immune from an endogeneity bias. Within this theoretical framework, we expect all the effects on participation linked to militancy to be channeled by the aid variable. However, any other random disturbance would also affect both the number of events and the aid variable simultaneously. Such co-movements could contaminate the estimate of the aid coefficient, thus creating a bias. The aim of this section is to investigate empirically this issue.

The present section provides a test for endogeneity bias due to Nakamura and Nakamura (1981), which is a version of the Hausman test (see e.g. Maddala, 1989). This testing procedure is based on the addition to the equation of the residuals from a reduced form equation explaining the suspected variable. Then, these authors have shown that the estimated coefficient for this test variable is an estimate of the endogeneity bias. In the case of the present model, this testing procedure can be understood easily by using the following notation. The model boils down to two simultaneous equations, with a recursive structure. 
An econometric equation corresponding to the structural attacks supply curve (8) may be written as:

$$
h_{i}=\alpha+\beta \theta_{i}-\gamma a_{i}+\varepsilon_{i} .
$$

From (10), we know that the aid allocation to each country can be expressed as a function of its militancy parameter, and $H$, which is common to all countries and can thus be neglected in a cross-country analysis. Assuming that a linear specification is acceptable, the corresponding econometric equation would read:

$$
a_{i}=\delta+\eta \theta_{i}+v_{i}
$$

The intercepts $\alpha$ and $\delta$ subsume in fact all the exogenous control variables that might be useful to include in an empirical application of this model. The two error-terms $\varepsilon_{i}$ and $v_{i}$ are the usual random disturbance terms included in econometric models. In this setting, it is quite natural, but not necessary, to assume that they are independently distributed. The reason for this judgment is that they capture the errors affecting the behavior of different agents. The former one describes the random shocks affecting the national players' behavior, while the latter captures the random disturbances affecting the donor. However, it all depends in fact on the common information that these agents are using when making their decisions, so that some cross correlation might exist. This is tested in the next section.

Then, combining (14) and (15) yields the econometric equivalent of the equilibrium locus described at proposition 2 and figure 1. It reads:

$$
h_{i}=\left(\alpha-\frac{\beta \delta}{\eta}\right)+\left(\frac{\beta}{\eta}-\gamma\right) a_{i}+\left(\varepsilon_{i}-\frac{\beta}{\eta} v_{i}\right) \text {. }
$$

If the interpretation offered in the previous section is right, then (16) is what has been estimated in section 2, at table 2, omitting to control for militancy. The test proposed in this section is to find an estimate for $v_{i}$, from an empirical equation corresponding to (15), and to add it to the equations presented at table 2. A glance at (16) shows that the corresponding coefficient will be an estimate of the endogeneity bias $-\beta / \eta$. 
Table 4: Reduced-Form ODA Equation (Equation 7)

$\begin{array}{cccc}\text { Variables } & \text { Coefficient } & \text { z-Statistics } & \text { p-value } \\ \text { Intercept } & 302.22 & 7.46 & 0.000 \\ \text { Population } & 5.66 & 8.74 & 0.000 \\ \text { (Population) })^{2} & -0.002 & -2.36 & 0.018 \\ \text { GDP p.c. } & -0.030 & -6.29 & 0.000 \\ \text { China and India } & -2295.00 & -3.19 & 0.001 \\ \text { West B. \& Gaza } & 273.69 & 1.16 & 0.25 \\ \text { Latin America } & -139.51 & -2.60 & 0.010 \\ \text { Sub-Saharan } & -20.66 & -0.41 & 0.680 \\ \text { OECD } & -571.62 & -3.08 & 0.002 \\ \text { “Camp David” } & 1683.06 & 9.89 & 0.000 \\ \text { USSR } & -148.19 & -2.06 & 0.039 \\ \text { ASEAN } & 179.36 & 1.56 & 0.122 \\ \text { Nb. Obs. } & 178 & & \\ R^{2} & 0.74 & & \end{array}$

Note: This equation has been estimated by a Tobit regression.

In our setting, the test is performed using the residuals from a Tobit regression explaining the amount of ODA received by each country. The dependent variable of the latter equation is the average amount of ODA received over the period 1990-2001. Because our sample includes both developed and developing countries, while only the latter are receiving any aid, this dependent variable is truncated at zero. The estimated ODA equation is presented in table 4 (equation 7).

Equation 7 is a reduced form equation aiming at explaining the average level of ODA received by each country, as a function of strictly exogenous variables only. Moreover, from our theoretical discussion, we know that we are looking for some political variables liable to capture the presence of some militant groups in the recipient country, even if they do so very 
imperfectly. Hence, beside some economic variables that measure somehow the need for aid, such as per capita GDP and population size, we include some more institutional variables. Population size is included with a quadratic form, as above. However, even per capita GDP is not orthogonal to some political characteristics. For example, Krueger and Maleckova (2003) show that it is strongly correlated with the index of civil liberty that they use in their equation. This is also true to some extent of the geographical dummy variables that we include, for indicating China and India, on the one hand, and Latin America and the Caribbean, on the other hand. For example, Huntington (1996) would probably favor an interpretation of these variables in terms of the civilizations that prevail in these countries. However, the fact that we have lumped together India and China gives this variable a definite demographic meaning, rather than one based on civilization. We include also a dummy variable for Sub-Saharan Africa, which is not significant, but is useful to have for performing the test for endogenity bias below. Notice that both Latin America and SubSaharan Africa have a negative coefficient, suggesting that, given their population size and their level of per capita GDP, these continents attract rather less ODA than the others. These effects, however, do not seem strongly significant in either case. More surprisingly, we also include the dummy variable for the West Bank and Gaza, which turned out insignificant. This suggests that the latter is not treated very differently, as far as aid is concerned, from the other countries in the Middle East, or Asia beside China and India, or Africa, for that matter.

The next two variables are definitely political, and might also capture some aspects of "militancy" for the indicated countries. There is first a dummy for the countries that joined the OECD before 1990, i.e. in fact before 1974. This excludes the countries that joined this organization after 1994, which might be deemed to self-select as far as aid is concerned. Then, we have included the "Camp David" countries, Egypt and Israel, which are known to benefit from a special treatment by the U.S.A., for reasons which are related to the model under test. Alesina and Dollar (2000) have also found that these countries benefit from a special treatment in the allocation of aid. The last two variables included might help to capture some other determinants of aid allocation than geography (civilization?) and militancy, and thus help identifying the model. The first one is a dummy indicating the 
former member countries of the USSR. This is a predetermined variable, which is significant with a negative sign. This suggests that these countries have not yet overcome the handicap accumulated during the cold war, and are still discriminated against by the aid allocation process, during the period covered here. Huntington (1996) would probably favor an interpretation of this variable also in terms of civilization, but this would not be very convincing. There are almost as many predominantly Muslim countries as there are Christian ones in this group, and the latter are far from homogenous, with the Baltic States standing apart from the Slav countries, where the Orthodox religion is dominant. Therefore, the negative coefficient for this variable suggests that the wake of the cold war matters probably to a large extent. The final variable is a dummy for the members of ASEAN having joined before 1990. These include the founding countries (Indonesia, Malaysia, Philippines, Singapore and Thailand), and Brunei, which joined in 1984. This grouping can hardly be interpreted as representing a "civilization" effect, in particular because many of the countries that Huntington would include in the "Sinic" group are missing here. This variable is borderline significant, with a positive sign. May be they were marginally favored by the aid allocation process because of their geographical proximity to mainland China, in order to keep the latter at bay. We also tried to include the Gini coefficient for each country, assuming that income inequality might be a source of militancy. However, this variable turned out insignificant. Probably, this says a lot about the quality of the data available regarding this variable, and their comparability across countries. Many of the variables kept in the specification presented are highly significant. Beside the "Camp David" one, all the more political dummy variables seem to be measuring in fact the lack of militancy, as they have all a negative coefficient, rather than the opposite. This is immaterial for the purpose at hand, as the more militant ones are then the reference countries. Equation 7 is then used for computing the residuals and the fitted value used in the equations presented below. 
Table 5: Test for Endogeneity Bias

\begin{tabular}{|c|c|c|c|c|c|c|c|c|c|}
\hline & Equation 8 & & & Equation 9 & & & Equation10 & & \\
\hline Variables & Coefficient & z-Statistics & $\mathrm{p}$-value & Coefficient & z-Statistics & $\mathrm{p}$-value & Coefficient & t-Statistics & $\mathrm{p}$-value \\
\hline Intercept & 0.36 & 2.17 & 0.030 & 1.30 & 32.06 & 0.000 & -0.64 & -0.17 & 0.86 \\
\hline ODA & 0.004 & 8.63 & 0.000 & 0.001 & 20.89 & 0.000 & 0.018 & 1.71 & 0.09 \\
\hline Population & 0.012 & 3.74 & 0.000 & 0.008 & 16.77 & 0.033 & 0.152 & 1.77 & 0.08 \\
\hline$(\text { Population })^{2}$ & - 1.58E-05 & -4.69 & 0.003 & $-6.34 \mathrm{E}-06$ & -16.37 & 0.000 & - 9.96E-05 & -1.36 & 0.18 \\
\hline Endog. Bias & -0.003 & - 2.57E-03 & 0.001 & -0.001 & - 1.34E-03 & 0.000 & -0.020 & -1.21 & 0.23 \\
\hline Nb. Obs. & 178 & & & 178 & & & 178 & & \\
\hline$R^{2}$ & - & & & - & & & 0.11 & & \\
\hline Pseudo- $R^{2}$ & 0.14 & & & 0.26 & & & - & & \\
\hline LR-Stat. (4 df) & 161.4 & & & 1682.4 & & & F-Stat.: 5.25 & & \\
\hline $\mathrm{p}$-value & 0.000 & & & 0.000 & & & 0.000 & & \\
\hline
\end{tabular}

Note: Equation 8 is a negative binomial regression estimated by quasi-maximum likelihood. Equation 9 is a Poisson regression, estimated by maximum likelihood. Equation 10 is a simple OLS regression. The dependent variable is the number of terrorist events originating from each country during the period 1990:01-2004:03. 
Table 5 presents the results of the test for endogeneity bias announced above. The starting point is the equations presented at table 2, to which the residuals from equation 7 have been added. They turn out to be highly significant in the two equations estimated using the integer count methods. These tests are thus rejecting the exogeneity assumption for ODA in the terrorist attacks equations presented at table 2. The negative signs of the estimated coefficients are in agreement with the prediction that can be derived from (16). Even in the OLS equation 10, the same negative sign is found. Notice in addition the estimated coefficients at table 5 are very similar to those presented at table 2 , suggesting that although it is significant, the endogeneity bias is very small in size.

\section{An Attempt at Identifying the Attacks Supply Curve}

The test for endogeneity bias performed above suggests that the dummy variables used in that exercise contain probably some relevant information for identifying the attackssupply curve (8). This section is devoted to investigating this issue. There is no doubt that the donor and the recipient governments are using in the real world a much richer information set than whatever we can capture by the use of some dummy variables. However, the econometric analysis performed in this section suggests that the identification problem can be mitigated to a certain extent by such an approach. However, the results must be regarded as a first cut at this issue, and simply call for more information gathering.

For identifying the attacks supply curve, the theoretical model presented at section 3 , and represented by a linear equation at (14), suggests to include some indicators of the degree of "militancy" faced by the recipient government along with the aid flow in the equation explaining the number of terrorist attacks emanating from each country. In this section, we are looking for a parsimonious equation where ODA comes up with a negative sign, consistent with the theoretical framework developed above. Then, the presence of some variables unrelated to militancy, and affecting also the aid allocation, as included in equation 3 above, would be enough for identifying the attacks supply curve. Table 6 presents the equations resulting from the addition to those presented at table 3 of two dummy variables, one indicating the West Bank and Gaza, and the other one indicating the "Camp David" 
countries, Egypt and Israel. These two dummy variables are probably the strict minimum addition to the estimated equations for capturing "militancy". On the other hand, these are the three countries on earth where the high level of militancy of the terrorist organizations cannot be disputed, in view of the frequency of terrorist attacks that we observe performed by citizens originating from them.

The most important point is that now, ODA comes up with a negative sign, as predicted by the theory of section 3, and specified at (14), whichever estimation method is used. This suggests that the set of dummy variables added in this equation does capture some relevant information about militancy that helps mitigating the identification problem raised above. Notice, however, that while several estimated coefficients are very similar across equations, with a small number of exceptions, ODA turns out insignificant in the Negative Binomial regression. Moreover, a $\chi^{2}$ test constructed as in section 2 above shows that the Poisson restriction is rejected by a wide margin. In other words, the jury is still out, as the econometric results presented here are somehow mixed. Nevertheless, the fact that the estimated sign for the impact of ODA is negative in the three equations is relatively encouraging, as is the fact that it is significant in both the Poisson and the OLS regressions. Hence, while the equations presented at table 2 were probably estimating the equilibrium locus of the model, the equations presented here are probably closer to a proper estimate of the structural attacks supply curve (8). The following exercise provides some clue about how close we are from the latter. 
Table 6: The Attacks Supply Curve

\begin{tabular}{|c|c|c|c|c|c|c|c|c|c|}
\hline & Equation11 & & & Equation12 & & & Equation13 & & \\
\hline Variables & Coefficient & z-Statistics & $\mathrm{p}$-value & Coefficient & z-Statistics & p-value & Coefficient & t-Statistics & $\mathrm{p}$-value \\
\hline Intercept & 0.90 & 5.43 & 0.000 & 1.33 & 23.18 & 0.000 & 3.33 & 1.70 & 0.09 \\
\hline ODA & $-1.96 \mathrm{E}-04$ & -0.44 & 0.659 & $-4.54 \mathrm{E}-04$ & -4.42 & 0.000 & -0.009 & -1.85 & 0.066 \\
\hline Population & 0.028 & 6.91 & 0.000 & 0.017 & 25.09 & 0.000 & 0.29 & 6.78 & 0.000 \\
\hline$(\text { Population })^{2}$ & $-2.30 \mathrm{E}-05$ & -7.01 & 0.000 & - 1.23E-05 & - 20.54 & 0.000 & - 1.75E-04 & -4.87 & 0.000 \\
\hline GDP p.c. & - 3.62E-05 & -2.94 & 0.003 & $-4.75 \mathrm{E}-05$ & $-4.75 \mathrm{E}-05$ & 0.000 & $-3.2 \mathrm{E}-04$ & -2.19 & 0.030 \\
\hline West B. Gaza & 5.18 & 5.09 & 0.000 & 4.94 & 68.31 & 0.000 & 401.38 & 24.34 & 0.000 \\
\hline “CampDavid" & 3.16 & 3.47 & 0.001 & 2.97 & 12.94 & 0.000 & 46.24 & 3.26 & 0.001 \\
\hline Nb. Obs. & 178 & & & 178 & & & 178 & & \\
\hline$R^{2}$ & - & & & - & & & 0.80 & & \\
\hline Pseudo- $R^{2}$ & 0.25 & & & 0.64 & & & - & & \\
\hline LR-Stat. (6 df) & 274.78 & & & 4214.31 & & & F-St: 113.92 & & \\
\hline $\mathrm{p}$-value & 0.000 & & & 0.000 & & & 0.001 & & \\
\hline
\end{tabular}

Note: Equation 11 is a negative binomial regression estimated by quasi-maximum likelihood. Equation 12 is a Poisson regression, estimated by maximum likelihood. Equation 13 is a simple OLS regression. The dependent variable is the number of terrorist events originating from each country during the period 1990:01-2004:03. 
Table 7: The Endogeneity Test for the Attacks Supply Curve

\begin{tabular}{|c|c|c|c|c|c|c|c|c|c|}
\hline & Equation14 & & & Equation15 & & & Equation16 & & \\
\hline Variables & Coefficient & z-Statistics & $\mathrm{p}$-value & Coefficient & z-Statistics & $\mathrm{p}$-value & Coefficient & t-Statistics & $\mathrm{p}$-value \\
\hline Intercept & 1.14 & 4.37 & 0.000 & 1.67 & 19.43 & 0.000 & 10.17 & 3.16 & 0.002 \\
\hline ODA & -0.001 & -1.23 & 0.219 & -0.001 & -6.54 & 0.000 & -0.033 & -3.23 & 0.015 \\
\hline Population & 0.030 & 6.50 & 0.000 & 0.021 & 18.67 & 0.000 & 0.378 & 7.02 & 0.000 \\
\hline$(\text { Population })^{2}$ & $-2.39 \mathrm{E}-05$ & -7.08 & 0.000 & - 1.47E-05 & - 17.01 & 0.000 & $-2.16 \mathrm{E}-04$ & -5.61 & 0.000 \\
\hline GDP p.c. & $-4.86 \mathrm{E}-05$ & -2.96 & 0.003 & - 7.14E-05 & - 7.14E-05 & 0.000 & $-6.51 \mathrm{E}-04$ & -3.42 & 0.001 \\
\hline West B. Gaza & 5.41 & 5.22 & 0.000 & 5.19 & 5.19 & 0.000 & 408.28 & 24.88 & 0.000 \\
\hline “CampDavid" & 4.49 & 3.09 & 0.002 & 4.67 & 11.37 & 0.000 & 86.41 & 4.20 & 0.000 \\
\hline Endog. Bias & 0.001 & 1.18 & 0.236 & 0.001 & 5.37 & 0.000 & 0.033 & 2.66 & 0.009 \\
\hline Nb. Obs. & 178 & & & 178 & & & 178 & & \\
\hline$R^{2}$ & - & & & - & & & 0.81 & & \\
\hline Pseudo- $R^{2}$ & 0.25 & & & 0.65 & & & - & & \\
\hline LR-Stat. (7 df) & 276.18 & & & 4245.42 & & & F-St: 102.12 & & \\
\hline $\mathrm{p}$-value & 0.000 & & & 0.000 & & & 0.000 & & \\
\hline
\end{tabular}

Note: Equation 14 is a negative binomial regression estimated by quasi-maximum likelihood. Equation 15 is a Poisson regression, estimated by maximum likelihood. Equation 16 is a simple OLS regression. The dependent variable is the number of terrorist events originating from each country during the period 1990:01-2004:03. 
The equations in table 7 are performing for this supply curve the same test for endogeneity bias as the one performed above. It adds to the previous equation the residuals from the reduced-form ODA equation presented at table 4 (equation 7). We find again some mixed results. The endogeneity bias is not significant in the Negative Binomial regression, with a p-value of $23.6 \%$, while it is highly significant in the other two equations. Here again, then, the jury is still out. A strong suspicion remains that ODA is in fact endogenous in these equations. Even in the Negative Binomial equation, the endogeneity bias is not very far from significant. However, it seems that the endogeneity problem is quite mild for estimating the structural attacks supply curve on this sample.

Hence, these results are rather comforting for our theoretical framework, although we are probably quite far away from using the rich information used by the donors and the recipient governments in their fight against terrorism, in the real world. Nevertheless, these results suggest that aid is delivered to some extent to recipient countries with a view to provide the right incentives for the recipient governments to fight terrorism within their sphere of influence.

\section{Conclusion}

We have first found a pretty robust empirical result showing that the supply of terrorist activity by any country is positively correlated with the amount of foreign aid received by that country. This has been estimated using three estimation methods, including the negative binomial, the Poisson, and the OLS regressions over a sample of 178 countries, including donors and recipients, as well as source and non source countries for terrorist attacks. A mistaken implication of this result would be to conclude that aid should be curtailed as part of the overall fight against terrorism. On the contrary, our model suggests that aid is delivered by the donor community to some extent as a way of purchasing some involvement by the recipient government in this fight. It is precisely because this aid is theoretically effective for reducing the supply of terrorist activity that the donor is delivering it in our model. However, the comparative statics of this model suggests that countries facing more militant activists should be granted more aid, in equilibrium, while they would 
also be the origin of more terrorist attacks. Hence, the co-movement of aid and terrorism originating from the recipient country is simply tracing out an equilibrium locus, and not capturing a proper structural equation that could directly be used for making policy recommendations. Then, we assume that both the donor and the recipient government benefit from an intimate knowledge of the degree of militancy of the activist groups that they are facing in the countries concerned, probably based on shared intelligence, which is not available to the researcher. It follows that the unobserved heterogeneity across countries is what is reflected in the positive relation found between aid and terrorist attacks. Some governments get more aid because they face tougher nuts to crack than others.

In order to test for this effect, we have used a standard test for endogeneity bias, due to Nakamura and Nakamura (1981). The residuals from an estimated reduced-form aid equation are used as a test variable in the terrorist attacks equation, and the resulting estimate leads to the rejection of the exogeneity assumption. In other words, our finding of a positive relation between aid and terrorist attacks is perfectly consistent with a model where aid is useful in providing the right incentives for the recipient governments to act effectively against terrorism within their sphere of influence. The root cause of the problem is that aid is endogenous with respect to terrorist attacks, in the sample used, as the donor chooses the pattern of aid allocation across countries taking into account the heterogeneous militancy that they are facing. However, in so doing, they use some information that is not available to the researcher, whose effect is in fact captured by the aid allocation variable. This analysis thus illustrates quite strikingly the general point that economists should be extremely cautious before drawing strong policy conclusions from empirical equations, unless the latter are derived from a tight analytical framework. Such policy conclusions are only warranted after the researcher has ascertained that his results concern a well-identified structural equation, and that all endogeneity biases have been corrected appropriately.

An admittedly imperfect attempt at identifying the attacks-supply curve has then been presented in section 5 . Although the dummy variables added to the equation are bound to control very coarsely for the missing information on "militancy", they allow somehow to improve the identification of the structural equation governing the supply of attacks from 
each country, although with some probable imprecision. Now, ODA comes up with the negative sign predicted by the theoretical model for this equation. Hence, the model presented provides a useful framework for understanding the convergence of the two results: an equilibrium locus is found with a positive slope, while the structural equation, although probably poorly estimated, comes up with a negative slope. These two equations are in fact derived from the same model, and capture two different relations. Despite the change in slope, they lead to the same policy conclusion, namely that aid is probably useful for fighting terrorism, and is to some extent delivered for that purpose. However, the former one is far from being redundant, as it teaches us additionally that (i) aid and the number of terrorist attacks per country are simultaneously determined, and (ii) asymmetric information is not a useful assumption to make in this case. This suggests that some further research would be worthwhile for documenting how far is intelligence shared between the donor and recipient countries, and what role is aid playing in this process.

We view these results as an invitation to do more work on the use of aid as a means to fight terrorism. The main predictions of the theoretical model seem to stand up reasonably well against the data, and the fact that a small set of variables is significant in explaining both ODA and the number of attacks per source-country is particularly intriguing. Nevertheless, a search for better indicators of militancy seems to rank high on the agenda. However, further research should also aim at a more direct test, trying to uncover the actual link between aid and reduced terrorism. Particularly relevant would be case studies that look at the change in counter-terrorist activity, including may be poverty-alleviation policy, undertaken in response to a change in the aid flow received. This topic has been neglected in the analytical literature so far. Counter-terrorism has been analyzed rather as a matter of retaliation or "crack down". Recent examples of analyses of the latter are found in Bueno de Mesquita (2005) and Rosendorff and Sandler (2004). Probably, one of the contributions of the present paper is to suggest that both types of anti-terrorism policy approaches, using the carrot and the stick, are in fact complementary. It is not the effectiveness of aid at reducing poverty that is at stake, but its role as an incentive for recipient governments to act more decisively against terrorism. Then, whether the recipient government favors poverty alleviation or 
"crack down" is a matter of strategy and of policy "ownership", tailored to the local conditions.

Appendix 1: Number of Events per Source Country (1990:01-2004:03)

\begin{tabular}{|c|c|c|c|c|c|}
\hline Country & Number & Country & Number & Country & Number \\
\hline West B. & 400 & Venezuela & 7 & Azerbaijan & 2 \\
\hline India & 227 & Ethiopia & 7 & China & 2 \\
\hline Colombia & 97 & Rwanda & 7 & Bolivia & 2 \\
\hline Israel & 58 & Yugoslavia & 7 & Kenya & 2 \\
\hline Iraq & 49 & Ireland & 6 & Kuwait & 2 \\
\hline Yemen & 49 & Italy & 6 & Chad & 2 \\
\hline Algeria & 47 & Jordan & 6 & El Salvador & 2 \\
\hline Pakistan & 45 & Cambodia & 6 & Liberia & 2 \\
\hline Angola & 41 & Japan & 5 & Macedonia & 2 \\
\hline Russian F. & 33 & Iran & 5 & Myanmar & 2 \\
\hline Spain & 31 & Bangladesh & 5 & Norway & 1 \\
\hline Turkey & 28 & Ecuador & 5 & Sweden & 1 \\
\hline Nigeria & 26 & U.S. & 4 & Czech Rep. & 1 \\
\hline Sri Lanka & 25 & Lebanon & 4 & Poland & 1 \\
\hline Peru & 22 & Somalia & 4 & Croatia & 1 \\
\hline Sierra Leone & 21 & Bosnia $\mathrm{H}$. & 4 & Libya & 1 \\
\hline Philippines & 19 & Sudan & 4 & Thailand & 1 \\
\hline Egypt & 19 & Afghanistan & 4 & Armenia & 1 \\
\hline Tadjikistan & 11 & Austria & 3 & Honduras & 1 \\
\hline Indonesia & 11 & Nepal & 3 & Eritrea & 1 \\
\hline Greece & 11 & Netherlands & 2 & Tanzania & 1 \\
\hline Uganda & 10 & Switzerland & 2 & Tunisia & 1 \\
\hline Burundi & 10 & Germany & 2 & Morocco & 1 \\
\hline U. K. & 9 & Argentina & 2 & Guinea & 1 \\
\hline Saudi Arabia & 9 & Chile & 2 & Nicaragua & 1 \\
\hline Georgia & 9 & Latvia & 2 & Senegal & 1 \\
\hline South Africa & 8 & Cuba & 2 & Emirates & 1 \\
\hline France & 7 & Malaysia & 2 & Zambia & 1 \\
\hline Bahrain & 7 & Panama & 2 & & \\
\hline
\end{tabular}

Source: ICT (http:/ / www.ict.org.il). 


\section{Appendix 2: Determination of Equilibrium $H$.}

Define the world's aggregate attacks supply curve as:

$$
H^{S}=\sum_{i} h_{i}\left(\theta_{i}, a_{i}\right)
$$

Then we know from (10) and figure 1 that $a_{i}$ may be written as a function of $\theta_{i}$ and H. It follows that:

$$
H^{S}=H^{S}(H)=\sum_{i} h_{i}\left(\theta_{i}, a_{i}\left(\theta_{i}, H\right)\right)
$$

Then, the full equilibrium of the model is a fixed point where $H^{S}=H$.

From (10), we know that increasing $H$ would reduce the common slope of all the attacks supply curves, entailing an increase in $a_{i}$ and a fall in $h_{i}$. Therefore, $H^{S}(H)$ is a decreasing function. Figure A1 illustrates the determination of the unique equilibrium $H$.

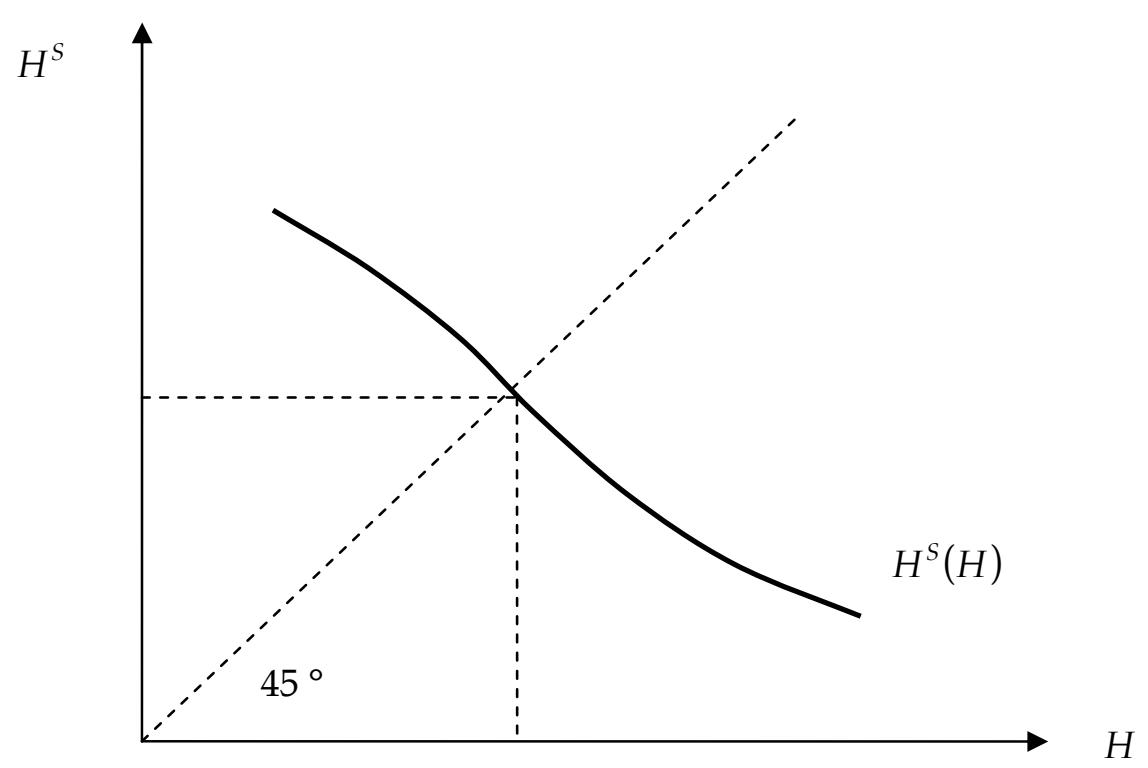

Figure A1: Determination of Equilibrium $H$. 


\section{References}

Adam, C. S. and O'Connell, S. (1999): “Aid, Taxation and Development in Sub-Saharan Africa", Economics and Politics 11 (3), 225-253.

Alesina, A. and Dollar, D. (2000): "Who Gives Aid to Whom and Why?", Journal of Economic Growth 5 (March), 33-63.

Azam, J.-P. (2005): "Suicide-Bombing as Inter-Generational Investment", Public Choice, forthcoming.

Azam, J.-P. and Laffont, J.-J. (2003): "Contracting for Aid", Journal of Development Economics $70(1), 25-58$.

Azam, J.-P. and T. Saadi-Sedik (2004): “Aid v. Sanctions for Taming Oppressors: Theory and Case Study of the Iraqi Kurds", Defence and Peace Economics, 15 (4), 343-364.

Berman, E. and D. D. Laitin (2003): “Rational Martyrs vs. Hard Targets: Evidence on the Tactical Use of Suicide Attacks", unpublished, Stanford University.

Berthélemy, J.-C. (2004): “Bilateral Donor's Interest vs. Recipients’ Development Motives in Aid Allocation: Do All Donors Behave the Same?", paper presented at the HWWA Conference on the Political Economy of Aid, Hamburg, 9-11 December 2004.

Berthélemy, J.-C., and A. Tichit (2004): “Bilateral Donors' Aid Decisions - A ThreeDimensional Panel Analysis", International Review of Economics and Finance, 13, 253-274.

Bueno de Mesquita, E. (2003): “The Quality of Terror", paper presented at the Institute on Global Conflict and Cooperation Conference on "Weapons of Mass Destruction and Terrorism", University of California at San Diego, August 2003 (forthcoming in American Journal of Political Science).

Bueno de Mesquita, E. (2005):"Conciliation, Counter-Terrorism, and Patterns of Terrorist Violence: A Comparative Study of Five Cases", International Organization, 59 (1),

Burnside, C. and D. Dollar (2000): “Aid, Policies, and Growth", American Economic Review 90, 847-868.

Chauvet, L. (2002): “Socio-Political Instability and the Allocation of International Aid by Donors", European Journal of Political Economy, 19, 33-59.

Delacroix, A. (2004): “The More I Give You, The More You Hate Me”, unpublished DEA dissertation, University of Toulouse. 
Feyzioglu, T., V. Swaroop, and M. Zhu (1998): “A Panel Data Analysis of the Fungibility of Foreign Aid", World Bank Economic Review, 12, 29-58.

Fleck, R. K. and C. Kilby (2004): “World Bank Independence: A Model and Statistical Analysis of U.S. Influence", paper presented at the HWWA Conference on the Political Economy of Aid, Hamburg, 9-11 December 2004.

Huntington, S. P. (1996): The Clash of Civilizations and the Remaking of World Order, Free Press: London (2002 ed.).

Krueger A. B. (2003): “Poverty Doesn't Create Terrorism”, New York Times, May 29.

Krueger, A. B. and D. D. Laitin (2003): “Kto Kogo? A Cross-Country Study of the Origins and Targets of Terrorism", unpublished: Princeton University.

Krueger, A. B. and J. Maleckova (2003): “Education, Poverty and Terrorism: Is There a Causal Connection?", Journal of Economic Perspectives, 17 (4), 119-144.

Laffont, J.-J. and D. Martimort (2002): The Theory of Incentives. The Principal-Agent Model, Princeton University Press: Princeton and Oxford.

Maddala, G. S. (1983): Limited-Dependent and Qualitative Variables in Econometrics, Econometric Society Monographs, Cambridge University Press: Cambridge.

Maddala, G.S. (1989): Introduction to Econometrics, Macmillan: New York.

Nakamura, A. and M. Nakamura (1981): “On the Relationships among Several Specification Tests Presented by Durbin, Wu and Hausman," Econometrica, 49, 1583-1588.

Rosendorff, P. and T. Sandler (2004): “Too Much of a Good Thing? The Proactive Response Dilemma", Journal of Conflict Resolution,

Svensson, J. (1999): “Aid, Growth and Democracy”, Economics and Politics 11 (3), 275-297.

Svensson, J. (2000): “When is Foreign Aid Policy Credible? Aid Dependence and Conditionality", Journal of Development Economics 61(1), 61-84.

Svensson, J. (2003): “Why Conditional Aid Does not Work and What Can Be Done about it?”, Journal of Development Economics 70 (2).

Wintrobe, R. (2002): "Religion and the Rationality of Suicide Terror", European Journal of Political Economy.

World Bank (1998): Assessing Aid: What Works, What Doesn't, and Why, A World Bank Policy Research Report, Washington, D.C.: World Bank. 